\title{
La fotografía en las fotonovelas españolas
}

\author{
Juan Miguel SÁNCHEZ VIGIL \\ jmvigil@ccinf.ucm.es \\ María OLIVERA ZALDUA \\ molivera@pdi.ucm.es \\ Departamento de Biblioteconomía y Documentación \\ Universidad Complutense de Madrid
}

Recibido: 08/02/2012

Aceptado: 15/03/2012

\section{RESUMEN}

Las fotonovelas cumplieron una función educativa en el sector de la sociedad con escaso acceso a la cultura. En España se editaron desde mediados de la década de los sesenta hasta finales de los años ochenta, alcanzando gran popularidad. Se caracterizaron por un contenido monotemático (narraciones amorosas) y por una hoja de estilo poco flexible. Se estudia en este artículo el uso de las fotografías en las fotonovelas españolas, tomando como referencia las principales colecciones editadas por las empresas especializadas. Se analiza asimismo el trabajo de los fotógrafos y se toma como modelo Lucecita, una de las publicaciones de mayor impacto a mediados de la década de los setenta del siglo XX.

Palabras clave: Edición especializada, fascículos, fotografía, fotonovela, Lucecita

\section{Photography in the Spanish Photo Romance Novels}

\begin{abstract}
Photo romance novels fulfilled an educational function in that sector of society which had limited access to culture. In Spain, they were published from the mid-sixties to the end of the eighties and were extremely popular. They were characterized by their mono-thematic content (romantic novels) and a not very flexible style sheet. This article studies the use of photographs in the Spanish photo novels, using as a reference the leading collections published by the specialized companies. The work of the photographers are also analyzed using as a model: Lucecita, one of the most popular publications in the mid1970s.
\end{abstract}

Keywords: Specialized publication, installments, photography, photo romance novel, Lucecita 


\section{INTRODUCCIÓN}

La fotonovela ha sido estudiada en España desde el punto de vista literario, sociológico y comunicativo (Carmona, 2002; Gubern, 1997; Alemán, 1975; Amorós, 1974), analizando sus valores textuales e icónicos de manera global. Sin embargo, no se han realizado estudios concretos sobre el uso y aplicación de la fotografía con los que comprender el impacto en el receptor. Considerada un subgénero literario, fue un instrumento de evasión y divertimento a través del que se produjo la alfabetización en las clases más bajas, al menos durante una década desde finales de los sesenta. Al contrario de lo que señaló Amorós (1969: 11), no fueron sus lectores/as "nuevos analfabetos" sino que el analfabetismo de la época -habían pasado ya treinta años desde el final de la guerra civil española- fue la causa del boom en nuestro país y en los de habla española, ya que las imágenes no necesitaban de un código preestablecido para su interpretación y la iconografía representaba, de manera simple y directa, los contenidos del argumento. A todo esto hay que añadir el componente social, el deseo de alcanzar la forma de vida idílica representada en las viñetas: familia feliz, vestuario, vehículos, viviendas, etc.

El Diccionario de la Real Academia ( $21^{\mathrm{a}}$ edición) define la fotonovela como "Relato, normalmente de carácter amoroso, formado por una sucesión de fotografías de los personajes, acompañados de trozos de diálogo que permitan seguir el argumento". Una definición limitada o incompleta porque no solo se generan imágenes de personas sino de paisajes, escenarios y objetos. La fotonovela es, efectivamente, un relato fotográfico secuencial en el que se combinan imagen y textos a modo de diálogo, siguiendo un argumento. Su principal objetivo es mostrar en imágenes una historia a partir de un guión. Se trata de un género híbrido basado en la creación de dos autores: el escritor (guionista) y el fotógrafo, aunque el estudio, salvo excepciones, se haya llevado a cabo desde el aspecto literario, subordinando generalmente la imagen o considerándola mera representación de los textos.

La industria editorial de los años sesenta y setenta alcanzó tiradas de medio millón de ejemplares por título, y formó parte de la cultura de masas (Gubern, 1997: 17): "Los comics y las fotonovelas son productos industriales, independientemente de su significación cultural, lo que supone un proceso productivo que se inicia con un texto y culmina con la difusión en papel impreso. En tal proceso intervienen gran número de personas y se aplican varias técnicas, además de maquilladores y estilistas, pero las figuras claves junto al guionista son el fotógrafo, el editor gráfico, encargado de la selección y el montaje de la narración. En las fotonovelas es necesaria la presencia de unos actores y de elementos de atrezzo". Desde el punto de vista literario, es importante considerar su influencia en la novela rosa que tuvo "una prolongación sugestiva dentro de las llamadas revistas del corazón, como en una pálida inyección de la fotonovela y su posología" (Alemán, 1975: 140).

En los años ochenta las fotonovelas fueron perdiendo interés paulatinamente, si bien algunos artistas la utilizaron para creaciones específicas, entre ellos Pedro Al- 
modóvar y Joan Fontcuberta. Almodóvar partió del guión de Las memorias de Patty Diphusa para crear la fotonovela porno Todo tuya, publicada en la revista El Vibora (1982) en la que Fabio McNamara interpretó a Cicciolina; en los setenta, Fontcuberta definió su trabajo Sputnik (1997) como "una fotonovela con argumento tecnocientífico". Las fotonovelas pasaron del papel impreso a la radio, en una doble versión de quiosco y radionovela, hasta que a finales de los años ochenta entraron en la televisión y comenzó la decadencia del modelo impreso. Los culebrones, servidos en capítulos diarios, engancharon al receptor y fueron una causa -la principal- de la quiebra del negocio editorial (Carmona, 2002).

Es objetivo de este trabajo investigar sobre el uso y aplicación las fotografías en las fotonovelas españolas, tomando como referencia las principales colecciones y títulos editados por las empresas especializadas, y analizando al mismo tiempo el trabajo creativo de los fotógrafos. La metodología seguida ha sido la recopilación y revisión de la bibliografía sobre la materia, incluida en el epígrafe correspondiente, y el análisis de las imágenes (cuantificación y valoración de contenidos), en un amplio trabajo de campo en un centenar de fotonovelas de propiedad particular, publicadas por las tres editoriales más significativas en la materia: Rollán, Bruguera y Alonso. Las colecciones seleccionadas se encuentran entre las más populares de la época estudiada: Coral, Corín Tellado, Lunela, Selena o Tentadora). Finalmente, de manera específica, se ha estudiado la fotonovela Lucecita, una de las de mayor impacto a mediados de la década de los setenta del siglo XX, editada por Agustín Quinto.

\section{REFERENCIA HISTÓRICA INTERNACIONAL}

Las fotonovelas nacieron en Italia en 1947 a partir de las cinenovelas o resúmenes de argumentos de películas ilustradas con una selección de fotos fijas del filme, un modelo que fue imitado en España en 1962 por la editorial Felicidad con libros dedicados a las grandes superproducciones de Samuel Bronston, entre ellas Rey de reyes y El Cid. El antecedente de la fotonovela fue el proyecto de los hermanos Alceo y Domenico del Duca, que lanzaron el 29 de junio de 1946 una novela ilustrada con dibujos basada en la serie estadounidense Gran Hotel. El éxito llevó a Stefano Reda y Giampaolo Callegari a publicar en 1947 la primera fotonovela con el título "Nel fondo del cuore" protagonizada por Gina Lollobrigida en la revista Il mio sogno. Semanas después salió la revista Bolero Film donde se publicaron Catene y Tormento (Sánchez Vigil, 2007: 230). Un lustro después Federico Fellini realizó una sátira neorrealista sobre el consumo de la fotonovela en la película El jeque blanco (Lo sceicco bianco, 1952), con un argumento en el que ridiculizaba a las lectoras y descubría la situación por la que pasaban las actrices para conseguir trabajo.

Las primeras empresas editoras fueron las italianas Lancio y Universo, que exportaron a Francia, Alemania, Reino Unido, España, Portugal, Noruega y Holanda. Lancio fue fundada en 1936 por Arturo Mercurio como empresa publicitaria, y a partir de 
los sesenta se convirtió en la mayor productora del género, editando hasta doce colecciones a la vez, entre ellas Kiss, Idilio, Gran Color, Sogno, Kolosal, Letizia, Charme, Ornela o Lunela, esta última comercializada todavía en 1996 bajo la dirección de Claudio Ferrero y con Claudio Morico como fotógrafo. En los setenta Lancio fue dirigida por Fernando Mercurio, que contó entre los guionistas con Giovanna Morini, Alia Rienzi, Antonella Tinazo, Vanna de Angelis, Alice Renzi, Jay Freeman, Vittorio Richelmy, Stelio Rizzo y A. Mosso. Los fotógrafos más destacados en ese periodo fueron Gianni Cavicechia, Mario Brambatti, Claudio Morico, Davide Bertucchini o María Brambatti.

En 1949 las fotonovelas pasaron a Francia y el 27 de junio salió Festival, de Editions Mundiales. E1 9 de agosto de 1950 se publicó la revista Nous Deux, que alcanzó una tirada de 350.000 ejemplares gracias a la inserción de fotonovelas; en 1957 Jean Jacques Bourgois abrió la agencia de prensa Art Presse Productions para la publicación de fotonovelas, temas publicitarios y de moda, que en una veintena de años (1957-1977) coordinó más de quinientos títulos. También en esa década proliferaron en Suiza y Bélgica, con títulos de gran difusión como Rêves, editada en 1956. Todavía en 1986, ya con el género en decadencia, Christian Creuzot y Olivier Nicolas crearon la editorial Les Films du Lezart, que mantuvo la producción durante tres años. 


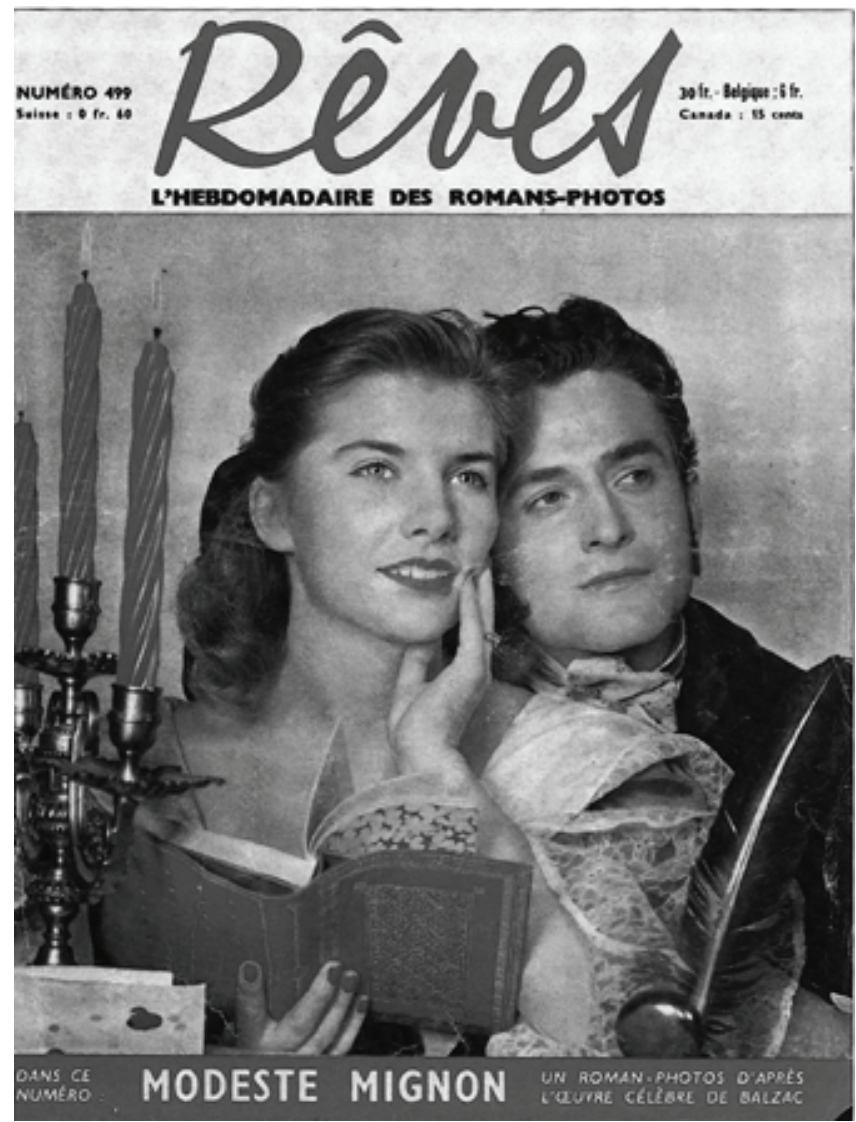

Fig. 1. Portada de la fotonovela belga Rêves, 1956

En Iberoamérica la fotonovela constituyó un extraordinario negocio. La escritora Marta Portal en declaraciones a la revista Gaceta Ilustrada el 2 de mayo de 1982 (Carmona, 2002) recordó en su visita a Bogotá en 1968 que en las cuenterías (quioscos) se exhibían más de veinte títulos de Corín Tellado: "Pero lo más curioso es que luego pude comprobar que las señoras elegantes del Country Club de la misma Bogotá solo leían a Corín Tellado". Este fenómeno fue estudiado en detalle por Germán Mariño en (1990).

En México el antecedente fue Santo, el enmascarado de plata (1956), de ediciones José G. Cruz, basada en la película del mismo título y de la que se imprimieron cada semana 900.000 ejemplares. La evolución ha sido estudiada por Rosalía Cruz Soto (2010), Irene Hernes (2009), Salvador Martínez (1986), y Raquel Altamira (1984). En los años sesenta llegaron a México las primeras fotonovelas italianas: $R u$ tas de pasión (1965) e Ilusión (1966), y en los setenta la industria editorial alcanzó su esplendor con gran actividad de las empresas EDAR (colecciones: Tuya y Amiga), 
Publicaciones Herrera, llamada después Novedades Editoriales (colecciones: Lo inexplicable, Casos de alarma, Linda, Dulce amor) y ElE (colecciones: Novelas de Amor, Cita, Ternura, Chicas y Citas de lujo), Editorial América (colección Sayonara), Editormex (colecciones: Sinfonía, Cariño, Lolita y Fascinación), y la editorial Andina (Libros y Publicaciones Periódicas).

En el resto de países de habla española la difusión y comercialización fue también masiva. En Argentina, por ejemplo, donde Roberto Flores realizó el estudio en Fotonovela argentina: heredera del melodrama (1995), la editorial Sigmar fue uno de los paradigmas, con la colección Susurros (1978) dirigida por Mario Lirio y M. Fouché. En Venezuela, la editorial Mabel publicó Mabel Colección y Extra de Mabel, dirigidas por Manuel Cerro González, con guión de L. Hauri, fotografía de S. Zannelli y documentación de V. Paolessi.

\section{LA FOTONOVELA EN ESPAÑA}

Las fotonovelas españolas tienen su origen en la novela rosa. En 1949 se experimentó al igual que en Italia con Gran Hotel, pero la venta fue suspendida y hasta 1958 no salió la revista Picnic que tradujo originales italianos. La popularización llegó en 1962 con la colección Cinéxito en la que se incluyó una selección de textos ilustrados de las principales películas en pantalla sobre artistas famosos (Joselito, Marisol, etc.) y superproducciones cinematográficas: Marisol en un rayo de sol (1962), Ha llegado un ángel (1962), Rey de Reyes (1963), El Cid (1963) y Marisol en Tómbola (1963). La serie pretendía recoger literaria y gráficamente el argumento, como se indica en el prólogo de Rey de Reyes: "En aras de una mayor espectacularidad e interés cinematográfico, la narración evangélica aparece aquí como novelada, con los siguientes aderezos, en algunas ocasiones, de situaciones y hechos más o menos verídicos, que son, en realidad, las pinceladas que un artista, como Samuel Bronston, ha introducido en el cuadro magnífico de la vida de Jesús".

A finales de 1966 aparecieron en los quiscos las primeras fotonovelas de Corín Tellado en la colección Corín Ilustrada, de la que en 1968 se ponía a la venta un título cada quince días con una tirada media de cien mil ejemplares, cifra que apunta Amorós y nos sirve de referencia (Martínez Luján, 1982: 144). Un año después media docena de editoriales publicaban cada semana doce series diferentes, analizadas por Andrés Amorós (1969: 6): "En estas fotonovelas de Corín Tellado aparecen fotografiados los ideales de una gran masa social...Muchas de estas fotonovelas están concebidas y realizadas a base de una mezcla del elemento erótico con el sentimental y están dirigidas a un público juvenil, que resulta alienado por una infraliteratura que incluye morbosamente ilustraciones que bordean lo prohibido". 


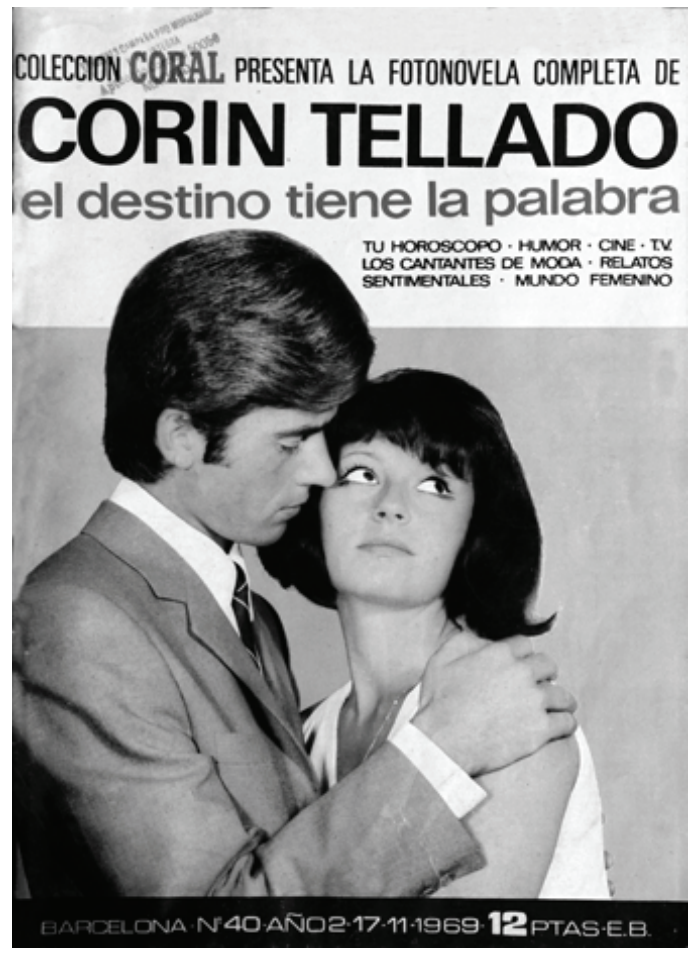

Fig. 2. Fotonovela de Corín Tellado

para la colección Coral de la editorial Bruguera, 1969.

En los años setenta algunos títulos superaron las expectativas de mercado, como Simplemente María (1972), pero el negocio fue general para todas las editoriales como señaló Amorós (1974:148): "Sí, por todas partes fotonovelas: en mi pueblecito de veraneo, en los quioscos de las grandes ciudades, en las librerías de las estaciones o aeropuertos, en la sala de espera, en los bolsos de las muchachas y en las manos de los hombres, en el metro". En los años de la Transición se publicaron fotonovelas eróticas y aumentaron las emisiones radiofónicas, entre ellas Lorena (1975) de Corín Tellado, emitida por 65 emisoras de la Red de Emisoras del Movimiento y la Cadena Azul de Radiofusión (REM-CAR).

En la década de los ochenta se empleó el término "fotoromance", con ejemplo en la serie Katty de la editorial Alonso, con guión del italiano Andrea Melotti y producción española de M. R. Aguado, bajo la dirección de Mariano Roma y con fotografías de Luis Guerrero. Por entonces la mayoría de las fotonovelas se importaban, como indicó Sandra del Río, coordinadora de la editorial Nueva Frontera (Martínez Luján, 1982: 144): "En la actualidad no puede hablarse de rentabilidad en este negocio. Su futuro se presenta bastante negro y todo porque la televisión con sus seriales nos ha comido terreno. No puedo decir la tirada, pero es mucho más baja que en años anteriores. Lo que no podemos es realizar las fotonovelas porque no disponemos de los 
medios suficientes. Las compramos a editoriales francesas e italianas y las traducimos". Aunque parecieron agotarse, todavía en los noventa continuaron en explotación. El 14 de abril de 1993 salió la revista Telenovela, editada por Hachette Filipacchi, dedicada a la información sobre el género con encartes de la fotonovela Primer amor.

\subsection{Las editoriales}

Las editoriales de mayor producción fueron Alonso, Bruguera, Editorpress, Mirasierra, Andina, Nueva Frontera y Rollán. Ediciones Alonso tuvo la sede en el número 4 de la calle Españoleto de Madrid y en 1979 presentaba cuatro series: Hortensia, Anabel, Katty y Cottell de Amor. Entre sus directores figuraron Mariano Romo y Víctor Scaph, y entre los guionistas Andrea Moletti y Jo Monray. Editorpress publicó la colección Mabel y Frenesí, y las series Ivanhoe, Kit Carson y Don Quijote, esta última en seis fascículos tomados de la película dirigida por Rafael Gil. Mirasierra aprovechó el periodo de apertura para publicar contenidos eróticos y tuvo entre sus directores a William Rotsler en 1977. Nueva Frontera, con la citada Sandra del Río como editora responsable, compró los derechos a empresas francesas e italianas, y editó hasta siete colecciones: Besos románticos, Sensación, Soñadora, Ámame, Revelación, Suspiros y Cupido.

Las dos grandes del sector fueron Bruguera y Rollán, ambas con experiencia en el género rosa. Bruguera, de larga tradición en el cómic, llegó a editar en 1959 hasta 16 colecciones semanales, entre ellas Coral, de Corín Tellado, que luego daría nombre a varias series. La editorial propuso a la escritora en 1977 el proyecto Lorena en dos versiones: serial radiofónico y fotonovela coleccionable, siguiendo los modelos de Corazón, Lucecita y Simplemente María. En 1982 todavía editaba tres colecciones de Corín Tellado: Coral (144.000 ejemplares), Corín Ilustrada (54.000 ejemplares) y Silvia (152.000 ejemplares), con el 60\% distribuido en Iberoamérica y Miami (Martínez Luján, 1982: 142-146).

La empresa de Manuel Rollán surgió en 1949 con el objetivo de publicar tebeos y novelas de bolsillo de diversos géneros (policíaco, western, bélico, romántico, etc.). En 1974 por problemas económicos se retiro del mercado del tebeo y se dedicó solo a la fotonovela, editando series de gran fuerza comercial: Corín Tellado, Cuerpos y Almas, Selene, Embeleso, Susurros, Sayonara y Gótica. Dirigió la empresa Alfonso Manzanares y su éxito se debió a la contratación de autores de renombre, entre ellos Carlos Santander, Marcial Lafuente Estefanía y Corín Tellado, después de que abandonara Bruguera por cuestiones económicas.

En 1982 cuatro editoriales abastecían todavía el mercado: Rollán, Bruguera, Andina y Nueva Frontera. La primera con tres series: Enamorada, Tentadora y Carlos Santander, pero con bajas ventas; Andina y Bruguera con tiradas simbólicas para publicitar las novelas rosas, mientras que Nueva Frontera sacaba todavía ocho colecciones: Besos románticos, Sensación, Soñadora, Ámame, Revelación, Suspiros y Cupido. Sandra del Río ya anunciaba su muerte en 1982: "Su futuro se presenta bastante ne- 
gro, y todo porque la televisión, con sus seriales, nos ha comido terreno" (Martínez Luján, 1982:146).

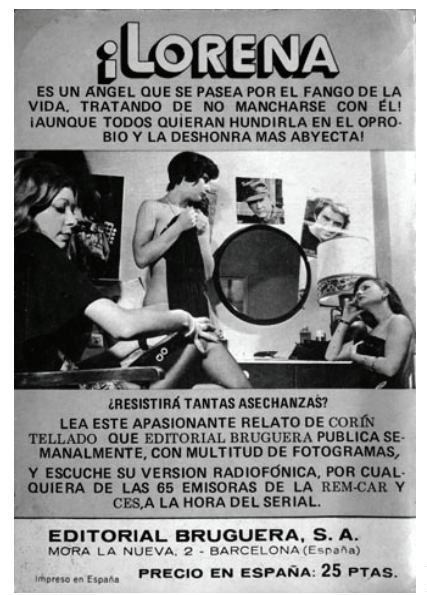

Figura 3 Publicidad de Lorena de la editorial Bruguera, 1977

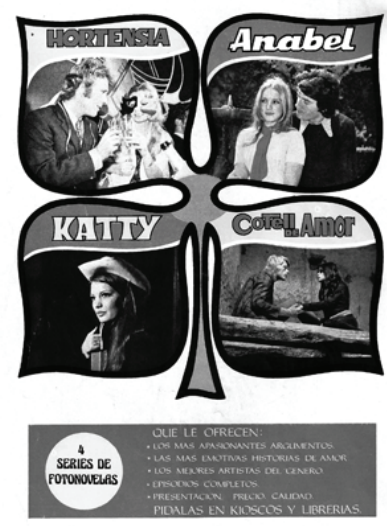

Fig. 4. Series de fotonovelas de la editorial Alonso, 1979

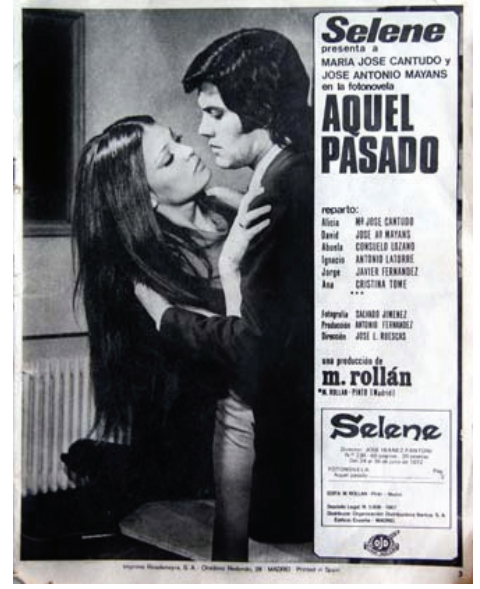

Figura 5. María José Cantudo y José Antonio Mayans fotografiados por Salvador Jiménez para la serie Selene de la editorial Rollán en 1967

\section{LA FOTOGRAFÍA EN LA FOTONOVELA}

En las fotonovelas se integraron los lenguajes icónico y verbal sobre un soporte en papel. Estos elementos, comunes con el cine, el cómic o la novela, presentaban un esquema narrativo con los personajes dentro de un marco espacial. A la fotonovela se 
pueden atribuir los mismos requisitos que Gubern señala para el cómic (1997:108): "La secuencia de viñetas consecutivas para articular un relato, la permanencia de al menos un personaje estable a lo largo de la serie, y los globos o bocadillos con las locuciones de los personajes inscritas en ellos". Maticemos que la narración fotográfica se basaba en la imagen fija, con un formato muy característico en cuanto al diseño o maqueta de la página.

En el centenar de novelas analizado se han cuantificado las fotografías, resultando una suma en torno a las trescientas imágenes por cada título. Hasta mediados de los años setenta se imprimieron en negro, excepto las cubiertas, con una media entre 48 y 64 páginas (pliego y medio o dos pliegos de 32 páginas). El color se incorporó a todos los pliegos en los primeros años setenta y supuso una elevada inversión en fotomecánica que derivó en la reutilización de las imágenes como explicó la actriz Ángela Bravo, protagonista de la fotonovela La llamaban Caridad, en una entrevista (Martínez Luján, 1982:142):

El trabajo no fue duro. Normalmente hacíamos el rodaje en una habitación $y$, si el guión exigía alguna foto de exterior, salíamos a los alrededores, pero no más lejos. En un día o dos estaba terminando. Por todo y por ser la protagonista me pagaban cinco mil pesetas, que en aquella época no estaba mal. Los actores teníamos que llevar nuestra propia ropa para los rodajes, pero esto no era lo peor. Lo malo era que, como en este género no existía derecho de reproducción, te encontrabas con que las fotografías que habían hecho para una fotonovela determinada las aprovechaban después para otras, cambiando, claro está el guión. Una faena ¿verdad?

Esta reutilización de las imágenes, provechosa para las empresas, constituía un fraude en el uso y aplicación de documentos, y generó un mercado interno al circular las fotos entre editoriales. Se abarataron así los costos de producción, pero se incumplió la norma básica del respeto a los derechos de autor.

Andrés Amorós (1974: 187) escribió que las fotonovelas estaban bien impresas y con un "alto nivel estético en buena parte de las publicaciones", cuestión que dependió del director de la publicación. En el repaso al centenar de ejemplares constatamos que la impresión fue muy desigual y que la estética fue encorsetada y poco imaginativa. Por lo que respecta a la compaginación, la estructura planteaba la narración en fotogramas o viñetas, de manera que cada una de las imágenes adquiría identidad propia al tiempo que formaba parte de un conjunto. Las maquetas eran poco originales, monótonas, sin apenas alteraciones, con un montaje repetitivo que solo ganaba interés cuando se combinaban imágenes horizontales y verticales, o en los planos generales que daban profundidad a los encuadres. En una primera etapa se superpusieron varias fotografías de formato menor, y en ocasiones se realizaron cortes verticales en forma de tiras. El esquema se fue haciendo más rígido y en consecuencia lineal, con el estereotipo de la foto única de presentación en la primera página más las 
seis de media a lo largo de la narración. En las fotografías de mayor formato se lucían personajes y decorados, lo que obligaba a los actores a trabajar la expresión del rostro.

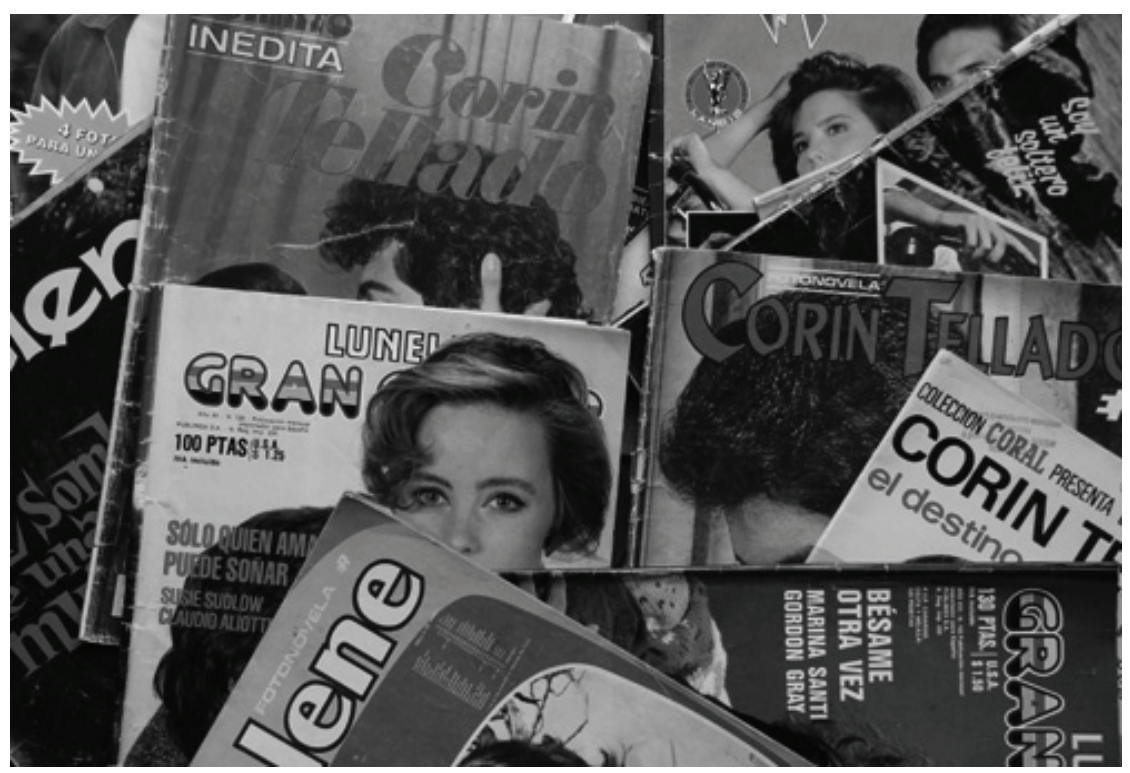

Fig. 6. Portadas de fotonovelas publicadas entre 1965 y 1980

A comienzos de los setenta la editorial Rollán dio a conocer a la actriz María José Cantudo junto al actor José Antonio Mayans con una producción de cuatro títulos mensuales. Sobre aquellos primeros trabajos, Cantudo comentó que el papel de los actores consistía en responder a situaciones concretas con gestos, por lo que la mayor valoración en las pruebas de selección era la "expresividad". Un ejemplo del trabajo de esta actriz se encuentra en Aquel pasado, de la serie Selene, producida por Antonio Fernández bajo la dirección de José Luis Ruescas, con fotografías de Salvador Jiménez. En esta fotonovela, de 56 páginas, se publicaron cerca de 300 fotografías en blanco y negro, combinadas en grupos de entre cuatro y seis imágenes, con profusión de primeros planos donde efectivamente el gesto daba sentido a cada viñeta. La estética de la época, previa al cambio democrático, roza los límites de la permisividad en un momento en el que la censura estaba vigente. Las tomas son correctas, con predominio de los primeros planos y un diseño monótono.

Imagen y texto conformaban un modelo conjunto en el que el texto jugaba el papel de hilo conductor, complementario o explicativo de la foto. Los planos empleados eran de todo tipo (primeros, medios, generales o americanos), con prioridad a los medios, y los textos se presentaban en globos, cuadros o bien como pie de foto. Las formas, tamaños y cortes de la viñeta añadían o restaban información, y las fotografí- 
as resultaron mas limpias cuando los textos se colocaron bajo las imágenes, sin pisar el original. Las dificultades para los profesionales estuvieron en conseguir los efectos y responder al guión con imágenes que representaran ideas o situaciones, por ejemplo el movimiento. Otros problemas fueron la limitación de los escenarios, la representación de sentimientos (dolor, amor, odio, pasión, etc.), y la muestra de los héroes y del ambiente en que se movían, de tal forma que se representaran los ideales de una gran masa social: chalets con jardines y piscina, mobiliario de lujo, decorados, etc.

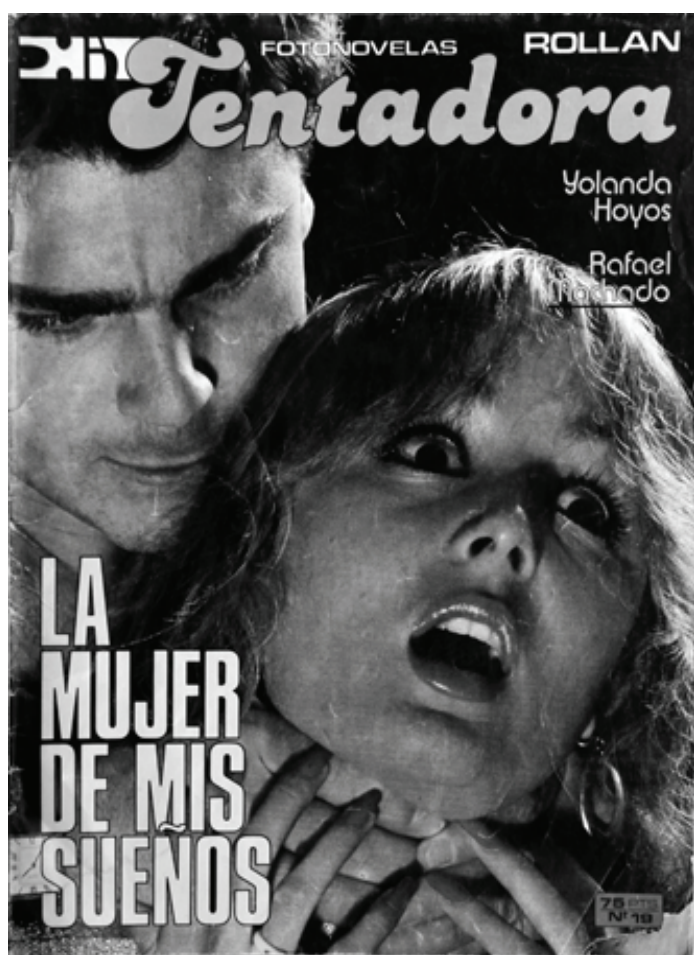

Fig. 7. Portada de la serie Tentadora, de Rollán.

Foto de Salvador Jiménez, 1966

Las fotos estaban mediatizadas por el diseño u hoja de estilo de la página. Según Amorós (1974:187): "Las fotografías simplifican la historia y en ocasiones no alcanzan la fuerza literaria". La relación texto-imagen es imprescindible, o mejor dicho es necesaria porque el significado de la imagen de cada viñeta viene explicado por las palabras. Así lo indica Sempere (1976:125): "Las fotos, más que tener una función narrativa con respecto al relato, tienen una función icónica o de cognición". No siendo las imágenes elementos narrativos per se, sin embargo son las que tienen mayor fuerza porque sugieren en la doble lectura denotativa y connotativa. Más allá de la 
relación con el texto, los escenarios despiertan o provocan otros intereses que los explicados, y lo mismo sucede con los personajes.

Los elementos clave en las fotografías fueron tres: retrato (personajes), paisaje (exterior) y decorados (interior), con el $90 \%$ de las imágenes en el primer apartado. Cada uno de ellos requería un tratamiento técnico adecuado: iluminación, encuadre, profundidad de campo, etc. Otro aspecto de interés fueron los efectos, que se resolvían mediante la iluminación y a veces con trucos o técnicas como la trama de líneas oblicuas para conseguir la lluvia. Del análisis de las fotografías en las fotonovelas españolas publicadas entre 1960 y 1990 resultan los siguientes datos:

\begin{tabular}{|l|l|}
\hline FORMATO & $\begin{array}{l}\text { El formato de la página (vertical) y la maqueta (hoja de } \\
\text { estilo) determinan el valor comunicativo de las imágenes }\end{array}$ \\
\hline TIPOLOGÍA & $\begin{array}{l}\text { La mayoría de las fotografías son retratos: personales, de } \\
\text { pareja o de grupo }\end{array}$ \\
\hline PLANOS & $\begin{array}{l}\text { Predominan los planos medios y americanos, habituales en } \\
\text { la representación de conversaciones entre personajes } \\
\text { Son excepcionales los planos picados o contrapicados } \\
\text { El exceso de planos medios consecutivos deriva en una } \\
\text { narración monótona }\end{array}$ \\
\hline TOMA & $\begin{array}{l}\text { Las tomas en exteriores son minoritarias, empleadas gene- } \\
\text { ralmente como recurso para cambiar de localización e in- } \\
\text { cluso de tema }\end{array}$ \\
\hline DETALLE & $\begin{array}{l}\text { Los detalles son también mínimos y se utilizan para resol- } \\
\text { ver los cambios temporales o espaciales }\end{array}$ \\
\hline RECURSO & $\begin{array}{l}\text { Se emplean como recurso: difuminados para mostrar re- } \\
\text { cuerdos o sueños, tramas de líneas oblicuas para efecto } \\
\text { lluvia, primeros planos para romper la monotonía, e ilumi- } \\
\text { nación especial a contraluz para captar el interés del lector }\end{array}$ \\
\hline
\end{tabular}

Después de la muerte de Franco, ya sin censura, el erotismo encubierto de las imágenes se transformó en detalles explícitos. Los textos continuaron plagados de tópicos y su relación con la imagen resultaba a veces incomprensible. Así en la fotonovela $E l$ precio de tu amor de la colección Katty $\left(\mathrm{n}^{\circ} 75,1981\right)$, donde una pareja pasea por el campo bajo esta cita: "La felicidad sonríe entonces a la joven pareja, solo enturbiada por las masculinas preocupaciones". En la última etapa editorial las fotonovelas se importaron porque resultaba más económico adquirir las fotografías y guiones de empresas italianas o francesas que invertir en la producción.

\subsection{Los fotógrafos}

El fotógrafo, siendo agente crucial en la realización de la fotonovela, ha sido ignorado en las investigaciones sobre la materia. Su vinculación con el editor fue margi- 
nal, al depender del director de cada proyecto. En determinados casos los nombres de los autores de las fotografías no aparecieron en los créditos, en evidente desprecio a los creadores. Por el contrario, muchos se especializaron e incluso hicieron escuela, entre ellos los italianos Carlo de Marchi, Fabrizio Albertini o Mario Padovan, quien produjo miles de imágenes para cerca de seiscientas fotonovelas entre 1950 y 1980 , encartadas en las revistas Noux Deux y Tele Poche, entre otras.

En la investigación sobre las fotonovelas españolas, editadas fundamentalmente por Bruguera y Rollán, encontramos una docena de fotógrafos con actividad continuada. La bibliografía no valora su aportación tan solo Andrés Amorós (1974:187) cita a Gerardo Cruz para comentar que "mostró un estilo sofisticado". Este autor publicó en la serie Selene de la editorial Rollán desde finales de los sesenta, y se caracterizó por encuadres imaginativos, motivos descentrados (objetos o sujetos), dar más aire en torno a los personajes, reducir el número de retratos y añadir escenas generales.

FOTÓGRAFOS Y EDITORIALES

\begin{tabular}{|l|l|}
\hline \multicolumn{1}{|c|}{ AUTOR } & \multicolumn{1}{c|}{ EDITORIAL } \\
\hline Antonio & Bruguera / Rollán \\
\hline Ballesteros, José María & Bruguera / Rollán \\
\hline Baños, Antonio & Bruguera / Rollán \\
\hline Bernardo, Emilio & Rollán \\
\hline Cruz, Gerardo & Rollán \\
\hline Echevarría, Carlos & Rollán \\
\hline Emilio & Rollán \\
\hline Ferré, M. & Editorpress / Rollán \\
\hline Gausa, Román & Editorpress / Rollán \\
\hline Guerrero, Luis & Alonso \\
\hline Heras, Luis & Rollán \\
\hline Jiménez, Salvador & Alonso / Rollán \\
\hline Lirio, Mario & Rollán \\
\hline Máximo & Bruguera / Rollán \\
\hline
\end{tabular}

José María Ballesteros trabajó primero para Bruguera y luego para Rollán. En su doble función de director y fotógrafo diseñó las hojas de estilo de la página y fue responsable del resultado final. A finales de los años sesenta sus planteamientos fueron clasicistas, manteniendo márgenes blancos alrededor de las imágenes, por lo que el resultado era más pulcro. Los posados de los actores son teatrales y por tanto poco creíbles, con gestos forzados.

Salvador Jiménez estuvo vinculado a la editorial Alonso y después a Rollán durante una quincena de años, entre finales de los sesenta y mediados de los ochenta. Trabajó en adaptaciones de obras literarias a fotonovelas, entre ellas La malquerida de Jacinto Benavente, publicada en 1973 por Rollán. En el análisis de sus imágenes se 
observa mayor variedad en las tomas, con planos frontales, picados y contrapicados, sin perder el predominio del retrato. En la serie Selene de la editorial Rollán juega con los primeros planos, muy destacados en el caso de María José Cantudo para Aquel pasado, publicada el 24 de julio de 1972. En las series de Corín Tellado de comienzos de los setenta la maqueta se libera, mezclando fotos verticales y horizontales en formatos cuadrados y rectangulares. La evolución fue significativa, y en 1982 aportó cientos de fotografías para las series Apasionada, Tentadora, Enamorada y Vengativa. Las imágenes son más frescas, presentadas en óvalos, bordes difuminados, tapados, picos y contraluces, con la pretensión de conseguir efectos. Los primeros planos son excelentes como la portada La mujer de mis sueños de la serie Tentadora, dirigida por M. Fouche.

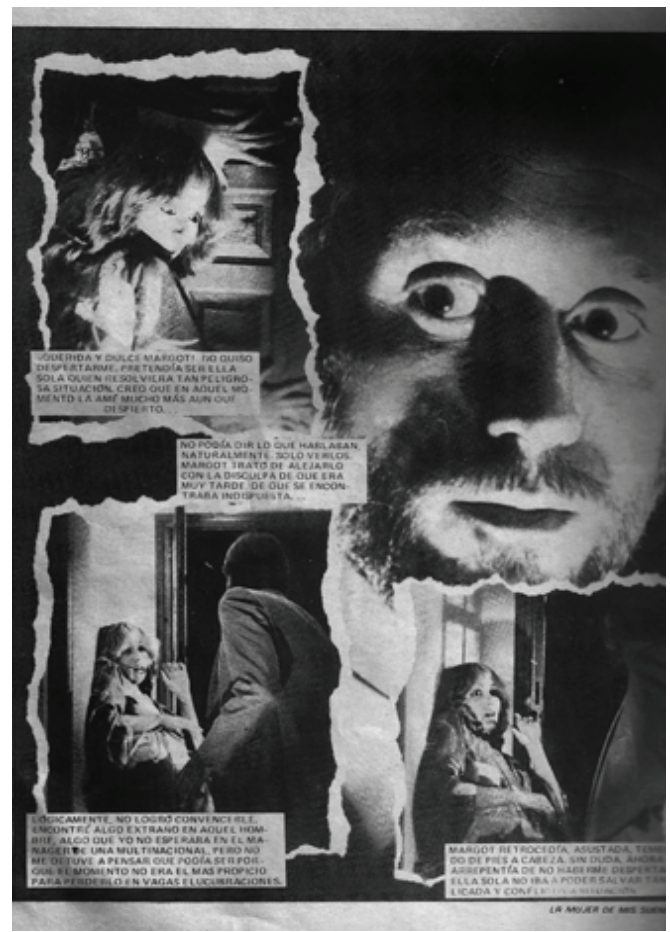

Fig. 8. Fotografías de Salvador Jiménez en

"La mujer de mis sueños", de Rollán, 1966

Antonio Baños también colaboró en Bruguera y Rollán. Fue el autor de gran parte de las fotos de la serie Corín Inédita de Rollán, caracterizada por la abundancia de planos medios de los actores. Su aportación, a pesar de las limitaciones de la maqueta, fue interesante cuando rompió los tópicos, aunque su trabajo resulta reiterativo. A mediados de los sesenta utilizó el retrato y los detalles como nexo de unión entre es- 
cenas, con excelentes fotos de los actores posando. Destacan las tomas frontales y de espaldas, siguiendo el esquema cinematográfico de plano y contraplano, y en los exteriores los picados y las vistas generales. Durante la Transición (1975-1980), libre de censuras, realizó imágenes con cierto erotismo dentro de la corriente denominada "destape". La norma fue entonces realizar numerosas fotos para un mismo tema, llegando a distribuir 12 fotos en una doble página para representar un beso. En ese periodo, con las imágenes todavía en blanco y negro, se observa una mejora en los retratos, una mejor iluminación al eliminar las sombras y el uso de la profundidad de campo. También como efecto, Baños usa las tramas de líneas oblicuas (Bajo el paraguas, de la serie Corinto de Bruguera, 1977). Las maquetas, sin embargo, apenas se modificaron, manteniendo la página dividida en cuatro y seis viñetas, salvo mínimas excepciones.

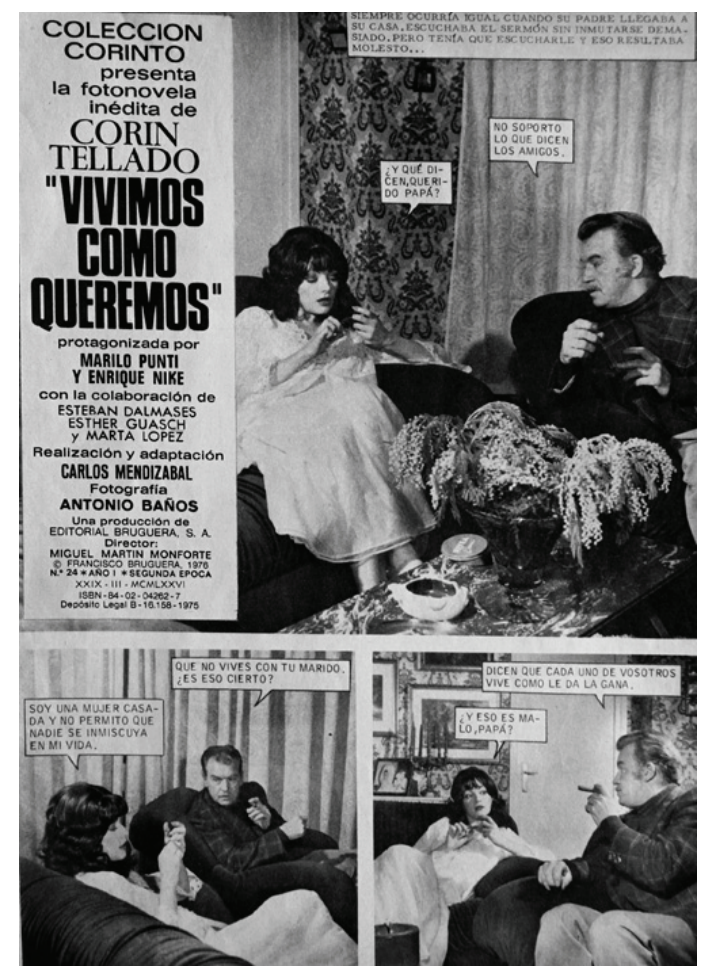

Fig. 9. Fotografías de Antonio Baños para "Vivimos como queremos", editada por Bruñera en 1975

Luis Heras trabajó a mediados de los setenta con la editorial Rollán, y sus fotos tuvieron un tratamiento diferente en cuanto al diseño. En la mayoría de las maquetas se cortaron las imágenes en tiras verticales y horizontales, eliminando ruido y dando 
sensación de movimiento. Utilizó superposiciones, óvalos, círculos y recuadros para dinamizar la narración, enriqueciendo así los habituales escasos recursos.

\section{LUCECITA COMO MODELO}

Un prototipo de fotonovela en la década de los setenta fue Lucecita, producto pensado para el consumo masivo con un guión que responde al contenido de las novelas rosas: truculenta historia de amor con final feliz. La publicó en 1975 A. Q. Ediciones, propiedad de Agustín Quinto, en 28 entregas de 20 páginas. El guión fue escrito por Delia Fiallo y se emitió por la cadena SER (Sociedad Española de Radiodifusión) de lunes a viernes a las cuatro de la tarde en los meses previos a la muerte de Franco.

La literatura es de baja calidad, con exceso de diminutivos y los diálogos, diseñados como pie de foto, son simples, reiterativos y faltos de imaginación, aunque cumplen la función orientadora con respecto a las imágenes. El argumento es decadente, lacrimógeno y se presenta en resúmenes plagados de tópicos.

FICHA TÉCNICA

\begin{tabular}{|l|l|}
\hline Dirección & Teófilo Martínez \\
\hline Argumento & Delia Fiallo \\
\hline Adaptación a fotonovela & Charo Sánchez del Arco \\
\hline Fotografía & Ferry \\
\hline Coordinación & F. Egozcuezabal \\
\hline Ayudante de producción & F. DINADER \\
\hline Maquillaje & Carmen Roca \\
\hline Peluquería & Amelia \\
\hline Actores principales & $\begin{array}{l}\text { Carmen Hernández (Lucecita) } \\
\text { Rafael Fernández (Gustavo) }\end{array}$ \\
\hline
\end{tabular}

El formato es tamaño folio, impresa en color y con cabecera simple, con la tipografía y la trama como reclamo. Todas las cubiertas se ilustraron con fotos en color a página, con un pie explicativo de los contenidos. El diseño interior es lineal, abriendo con un plano general a página y cerrando de la misma manera. 


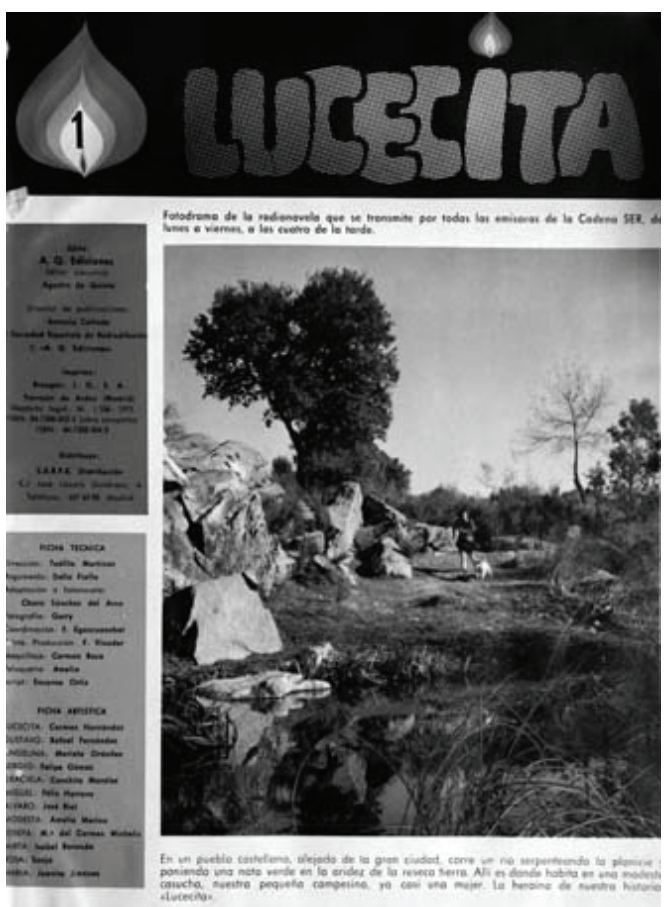

Fig. 10. Portada del n ${ }^{\circ} 1$ de Lucecita. Foto de Gerri, 1975

Se publicaron más de 2000 fotografías, con una media de media de 75 viñetas por fascículo distribuidas generalmente en grupos de cuatro, si bien la maqueta muestra desde dos a seis fotos, y solo una de manera excepcional. En el desarrollo se combinan de dos a seis fotografías rectangulares o cuadradas, todas en color y bien reproducidas de acuerdo a la técnica del momento. Se distribuyen como los fotogramas de un filme, excesivos e innecesarios muchas de las veces.

La unidad narrativa se consigue con la imagen, repitiendo al inicio de cada fascículo la fotografía final del anterior. En las escenas dramáticas, donde los actores adoptan poses teatrales, la composición pasa a primer plano, con mayor número de picados y contrapicados para enfatizar. Se utilizaron todo tipo de planos, si bien la mayoría de los encuadres se corresponden con planos medios. La mayor parte de las imágenes fueron tomadas en interiores, con decorados sobrios para no quitar protagonismo a los actores. En resumen, las fotografías realizadas por Gerry para la fotonovela Lucecita son rígidas, estáticas, con encuadres correctos y sin ningún valor creativo. 

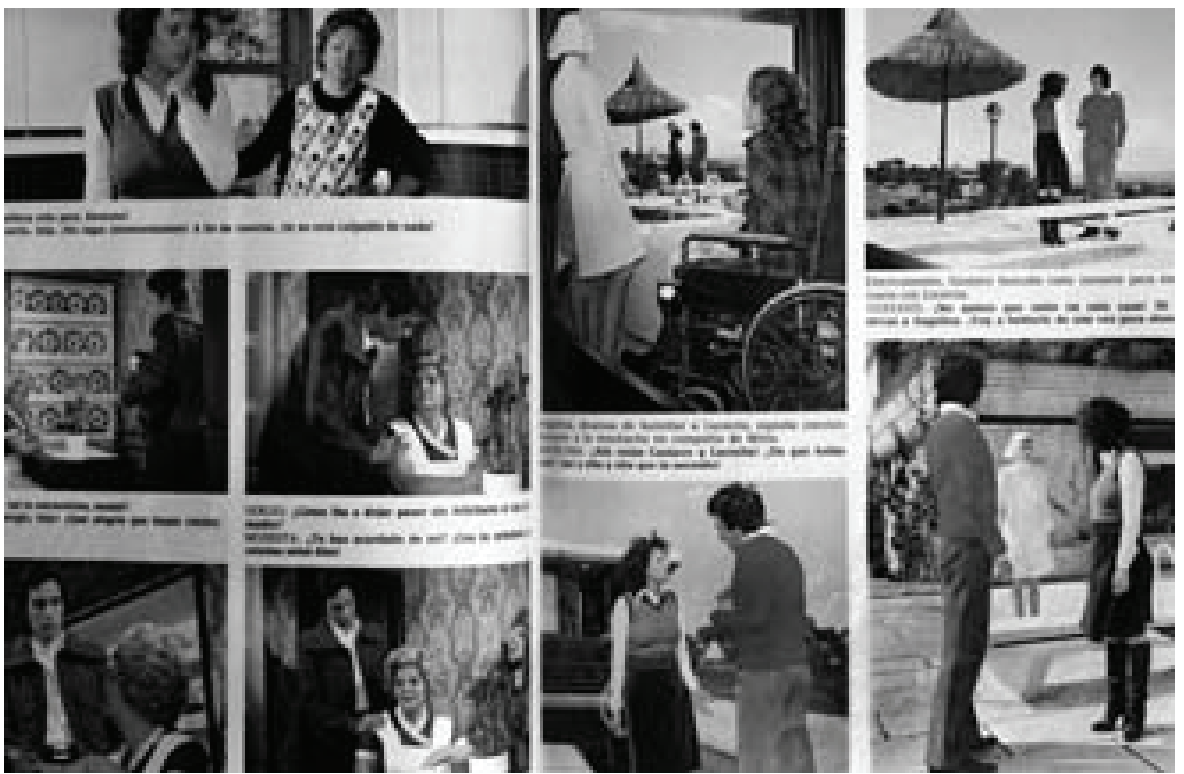

Fig. 11. Doble página de Lucecita.

Fotografías de Gerri, 1975.

\section{CONCLUSIONES}

La producción de fotonovelas en España fue extraordinaria, con tiradas en torno a cien mil ejemplares por título, y una media estimada de trescientas fotografías distribuidas entre cuarenta y ocho y sesenta y cuatro páginas. Se caracterizaron por mantener un formato y diseño similar de acuerdo a las hojas de estilo: portada en color con fotografía de impacto, e interior estructurado en viñetas en blanco y negro, cuadradas o rectangulares.

La estructura narrativa se basó en los fotogramas y en los textos explicativos, que evolucionaron desde los globos insertados sobre la propia imagen hasta los pies de foto al estilo tradicional. El lector aprendió a seguir el argumento desde la imagen en su relación con los textos, por lo que la fotografía cumplió una función comunicativa, además de ilustrativa, al representar los significados del guión.

La evolución de las fotonovelas fue paralela al desarrollo de la técnica fotográfica, de la fotomecánica y de las artes gráficas. La fotografía en color se fue aplicando paulatinamente desde comienzos de los años setenta, ganando en la presentación pero perdiendo fuerza expresiva.

Asimismo, se constata que la fotonovela influyó en la especialización de los profesionales de la fotografía, con dos características específicas en su función: el dominio del retrato y de la iluminación. Se dan a conocer los principales autores en la especialidad, entre ellos José María Ballesteros, Salvador Jiménez y Antonio Baños. 


\section{BIBLIOGRAFÍA}

ALEMÁN SAINZ, Francisco (1975). Las literaturas del kiosko. Barcelona: Planeta. ALONSO, Manuel y MOTILLA, Luis (2001). "La fotonovela", en Imágenes en acción. Madrid: Akal, pp. 152-157.

ALTAMIRA ECUTI, Raquel (1984). Análisis del discurso de la imagen secuenciada en la fotonovela. México: UNAM.

AMORÓS, Andrés (1969). "Infraliteratura y alienación”, en Ínsula, junio, n² 271, pp. 6-7.

-(1974). "Corín Tellado quince fotonovelas completas, seleccionadas entre las mejores", en Subliteraturas. Barcelona: Ariel, pp.151-152.

BRAVO, Anna (2003). Il fotoromanzo. Bologna: Il Mulino.

CARMONA, Ángeles (2002). "Auge y decadencia de la fotonovela", en Corín Tellado. El erotismo rosa. Madrid: Espasa, pp. 156-161.

CHIROLLET, Jean Claude (1983). Esthétique du photoroman. París: Mediathèque Edilig.

CRUZ SOTO, Rosalía y ROJAS, Romeo (2010). "La fotonovela en México", en Comunicación e ideología, $\mathrm{n}^{\circ} 4$, pp. 39-79.

-(1977). La fotonovela en México. Sintesis y análisis de una vida llena de amor. México: UNAM.

CURIEL, Fernando (1978). Fotonovela rosa, fotonovela roja. México: UNAM.

FLORES, Roberto D. (1995). Fotonovela argentina: heredera del melodrama. Buenos Aires: Asociación Argentina de Editores de Revistas.

GUBERN, Román (1997). Medios icónicos de masas. Madrid: Historia 16.

HERNES, Irene (2009). Mitos y monitos: historietas y fotonovelas en México. México: Nueva Imagen.

LECOEUVRE, Fabien y TAKODJERAD, Bruno (1991). Les années Roman-Photos. París: Veyrier.

MARIÑO, Germán (1990). Fotonovela. Colombia: Enda América Latina.

MARTÍNEZ LUJÁN, María Dolores (1982). "El regreso de la novela rosa", en Los domingos de Abc, 28 de febrero, pp. 142-146.

RAMÍREZ, Juan Antonio (1981). "La historieta y la fotonovela", en Medios de masas e historia del arte. Madrid: Cátedra, pp. 194-223.

SAINT-MICHEL, Serge (1979). Le roman-photo. París: Larousse.

SAINZ, Francisco (1975). Las literaturas del kiosko. Barcelona: Planeta.

SALVADOR MARTÍNEZ, Venancio Pablo (1986). Viñeta mía que estas en el medio: análisis de un discurso. La fotonovela. México: UNAM.

SÁNCHEZ VIGIL, Juan Miguel (2007). "Fotonovela", en Del daguerrotipo a la Instamatic. Gijón: Trea, pp. 230-231.

SEMPERE, Pedro (1976). Semiología del infortunio: lenguaje e ideología de la fotonovela. Madrid: Felmar. 
STEIMBERG, Oscar (1977). Leyendo historietas. Estilos y sentidos en un "arte menor”. Buenos Aires: Ediciones Nueva Visión. 